\title{
NOTE UPON THE GERMICIDAL ACTION OF THE DISINFECTANTS KEROL AND CYLLIN UPON VIRULENT TUBERCLE BACILLI IN SPUTUM.
}

\author{
BY WILLIAM G. SAVAGE, B.Sc., M.D., D.P.H., \\ Medical Officer of Health, Colchester.
}

There is, at the present time, great need for reliable data as to the ability of some of the more powerful disinfectants to kill tubercle bacilli under conditions identical, or, at least, comparable, with those met with in practice.

The ordinary Rideal-Walker determination of the relative value of disinfectants tested against the typhoid bacillus, gives no means of reliable deduction as to the power of the disinfectant to kill tubercle bacilli in suptum.

Data, as to the ability of chemical disinfectants to kill tubercle bacilli in sputum, can only be obtained by direct experiment, including inoculation into animals. The distinction between tubercle bacilli in a moist state and when dried must always be kept in mind. It is well known that tubercle bacilli can be dried without causing their death, and in such a condition are highly resistant, and this is particularly the case when enveloped in dried expectoration.

The following results were obtained in a recent series of experiments. Three hours was taken as a convenient time of exposure and one which could, for many articles and surfaces, be attained in practice. Fresh sputum from an advanced case of consumption was used. On microscopic examination it showed very numerous tubercle bacilli. The sputum was spread thickly upon both sides of wooden slips, which were then suspended in a desiccator over sulphuric acid. The sputum was apparently quite dry on all the slips after two days, but they were kept in the desiccator for two additional days.

Freshly-made-up solutions of cyllin and kerol were prepared, the strengths being exactly as indicated below. The wood slips were completely immersed in these solutions for exactly three hours, at room temperature, which was $10^{\circ} \mathrm{C}$. The slips were then removed and each gently washed in sterile water. The sputum was then scraped off from each slip into a sterile watch glass, made into an emulsion with a little sterile water, and then, as far as possible, the whole was injected subcutaneously into a guinea-pig, under suitable antiseptic precautions. In all, nine animals were inoculated in this way. One 
of them was a control, and for this purpose the sputum slip was suspended in sterile water instead of disinfectant; otherwise as above. All the inoculations took place on the same day. The animals were kept under hygienic conditions for a month (thirty days), and then were killed and post-mortem examinations made at once.

The results are shown in the table:-

+ signifies that the animal developed tuberculosis, and that the typical glandular enlargements on the side of inoculation were present, and that in every case tubercle bacilli were demonstrated in coverslip preparations made from the enlarged lumbar glands or the spleen.

- signifies that there was no evidence of tuberculosis, no trace of glandular enlargement, and that no tubercle bacilli could be demonstrated in any of the glands.

\begin{tabular}{|c|c|c|c|}
\hline Dilution employèd. & Kerol. & cyllin. & Time of expostre. \\
\hline 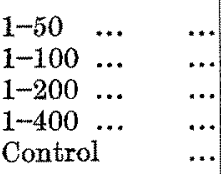 & $\begin{array}{l}- \\
- \\
+ \\
+\end{array}$ & $\begin{array}{l}- \\
- \\
+ \\
+\end{array}$ & $\begin{array}{c}3 \text { hours } \\
\text { " } \\
"\end{array}$ \\
\hline
\end{tabular}

This table shows that both disinfectants yielded precisely similar results. For both, a 1 per cent solution was capable of killing tubercle bacilli in three hours under the conditions of the experiment. The only difference between the two series of results was that the guineapig inoculated with the sputum exposed to 1-200 cyllin showed very marked tuberculosis and had lost considerably in weight, while the corresponding guinea-pig inoculated with the sputum exposed to 1-200 kerol had gained considerably in weight, and only showed a comparatively slight degree of tuberculosis. This may possibly, however, be due to inequality of dose, since it is impossible to be certain that an equal number of tubercle bacilli are spread on each slip.

It should be remarked that the conditions of the test were intentionally made very severe. The sputum was one containing very many tubercle bacilli, and was spread in thick layers, thus ensuring that a protective coating of mucus was present, while also the sputum was dried very thoroughly. The tubercle bacilli were, therefore, in as highly a resistant state as possible, and that 1 per cent solutions of these disinfectants are capable of killing virulent tubercle bacilli in three hours under these conditions is, I think, very satisfactory. 